\title{
Effect of Ethanol on Iontophoretic Transdermal Delivery of 5-Aminolevulinic Acid through Yucatan Micropig Full- thickness Skin
}

KAZUSA ASAI, A. OCHIAI ${ }^{1}$, N. KAWASHIMA ${ }^{1}$ AND Y. TOKUOKA ${ }^{1 *}$

Graduate School of Engineering, ${ }^{1}$ Faculty of Biomedical Engineering, Toin University of Yokohama, 1614 Kurogane-cho, Aobaku, Yokohama 225-8503, Japan

\author{
Asai et al.: Effect of Ethanol on Iontophoresis of ALA
}

\begin{abstract}
The effect of ethanol was investigated on iontophoretic transdermal delivery of 5-aminolevulinic acid through Yucatan micropig full-thickness skin. When $20 \%$ ethanol was added into an aqueous 5-aminolevulinic acid solution, the iontophoretic permeation of 5-aminolevulinic acid through Yucatan micropig full-thickness skin was enhanced. The addition of ethanol also enlarged the partition of 5-aminolevulinic acid into Yucatan micropig full-thickness skin, which gave rise to enhancement of 5-aminolevulinic acid permeation. This result suggested that the combination system of iontophoretic delivery and $20 \%$ ethanol could be a promising approach for the promotion of 5-aminolevulinic acid skin permeation.
\end{abstract}

Key words: Iontophoresis, 5-aminolevulinic acid, ethanol, Yucatan micropig full-thickness skin, permeability coefficient, diffusion coefficient, partition coefficient, lag time

5-Aminolevulinic acid-based photodynamic therapy (ALA-PDT) is one of the most effective treatments of skin diseases such as cutaneous carcinoma and intractable acne ${ }^{[1-4]}$. In ALA-PDT, ALA is administered topically, and an endogenous photosensitizer, protoporphyrin IX (PpIX), is accumulated in skin diseases. When PpIX is photoexcited by light with a specific wavelength ranged from 600 to $700 \mathrm{~nm}$, it transfers the energy to molecular oxygen and forms cytotoxic singlet oxygen, leading to photochemical and photobiological processes that cause irreversible photodamage to the skin disease $\mathrm{e}^{[5-7]}$.

Skin has an outermost thin layer, stratum corneum and underlying viable epidermis and dermis. Since the stratum corneum is highly hydrophobic, dry, and a percutaneous barrier, hydrophilic compounds are inferior to hydrophobic compounds in permeating through the stratum corneum ${ }^{[8]}$. When ALA is topically applied to skin diseases in ALA-PDT, it is hard for ALA to permeate into the stratum corneum because of its hydrophilicity. In fact, in the clinical treatment of solar keratosis lesion and Bowen's disease by ALAPDT, ALA is passively administered by percutaneous absorption for $4-6 \mathrm{~h}$ before light irradiation ${ }^{[9]}$. The long-time administration makes it difficult to establish ALA-PDT as a standard treatment modality and to

*Address for correspondence

E-mail: tokuoka@toin.ac.jp apply to outpatients. Therefore, skin permeation of ALA needs to be improved.

Iontophoresis is a process to enhance skin permeation of ionized and charged compounds by application of a weak electrical current. So far, many researchers have studied iontophoresis for improving skin permeation of various types of drugs, insulin ${ }^{[10,11]}$, methotrexate ${ }^{[12]}$, metoprolol ${ }^{[13]}$, indomethacin ${ }^{[14]}$, luteinizing hormone releasing hormone ${ }^{[15]}$, and so on. Besides, iontophoretic delivery can be applied to skin permeation of $\mathrm{ALA}^{[16-21]}$. As a result, iontophoresis can significantly enhance permeation of ALA across skin when compared to passive transdermal delivery. For example, the amount of ALA that passively diffuses across human stratum corneum in several hours can be delivered by the iontophoresis in $10 \mathrm{~min}$ or less ${ }^{[18]}$; iontophoresis could enhance human epidermal permeation of ALA by 15 -fold ${ }^{[21]}$.

Recently, other techniques such as ultrasound, electroporation, and chemical enhancers have been

This is an open access article distributed under the terms of the Creative Commons Attribution-NonCommercial-ShareAlike 3.0 License, which allows others to remix, tweak, and build upon the work non-commercially, as long as the author is credited and the new creations are licensed under the identical terms

Accepted 15 December 2018

Revised 05 May 2018

Received 11 December 2017

Indian J Pharm Sci 2019;81(1):177-181 
combined with iontophoresis ${ }^{[22]}$. The combination system seems to be more effective for transdermal delivery compared with the iontophoresis system alone. Moreover, ethanol is well known as a topical penetration enhancer and is often used in transdermal delivery systems ${ }^{[23]}$. Ethanol extracts lipids and proteins exerting a percutaneous barrier function on stratum corneum; thereby accelerating skin permeation of drugs.

In the present investigation, in order to enhance percutaneous ALA absorption within a shorter time, we determined in vitro iontophoretic transdermal delivery of ALA through Yucatan micropig (YMP) fullthickness skin with and without ethanol, evaluating the effect of the combination of iontophoresis and ethanol on ALA skin permeation.

YMP full-thickness skin employed for in vitro iontophoretic permeation experiments was purchased from Charles River Laboratories Japan, Inc. ALA (98 \%) was obtained as ALA hydrochloride from Cosmo Bio Co., Ltd. Ethanol (99.5 \%), acetylacetone (99.5 \%), formaldehyde (36.0-38.0 \%), sodium chloride $(99.5 \%)$, and agar (powder) were purchased from Kanto Chemical Co., Inc. A 4-(2-hydroxyethyl)1-piperazineethanesulfonic acid (HEPES) buffer solution was prepared with 4-(2-hydroxyethyl)-1piperazineethanesulfonic acid and an aqueous sodium hydroxide solution $(0.1 \mathrm{~mol} / \mathrm{l})$, which were purchased from Nacalai Tesque, Inc. All of the materials were used without further purification.

In vitro iontophoretic permeation experiment of ALA with and without ethanol through YMP full-thickness skin was carried out with the iontophoretic device described in fig. 1. YMP full-thickness skin was settled on the receiver compartment having an inner volume of $150 \mathrm{~cm}^{3}$. The anode cell (donor compartment) was filled with $0.6 \mathrm{~mol} / 1(100 \mathrm{mg} / \mathrm{l})$ ALA solution prepared using distilled water with and without ethanol. The cathode cell and the receiver compartment were filled with the HEPES buffer solution $(\mathrm{pH}=7.4)$ containing $133 \mathrm{mmol} / \mathrm{l}$ sodium chloride. The platinum electrodes fixed in the anode and cathode cells by using agar gel containing $0.9 \%$ sodium chloride were connected to a constant current source (HA-3001A, Hokuto Denko Corporation), and a current density of $0.132 \mathrm{~mA} / \mathrm{cm}^{2}$ was applied at $37^{\circ}$ for $6 \mathrm{~h}$. The effective diffusion area on the skin was $3.8 \mathrm{~cm}^{2}$. A $200 \mu \mathrm{l}$ of HEPES buffer solution from the receiver compartment was collected at specified time intervals. The concentration of ALA permeated through the YMP skin was measured, and the cumulative amount of permeated ALA per unit skin area was calculated.

The concentration of ALA permeated through the YMP full-thickness skin into the buffered solution in the receiver compartment was measured by the fluorometric method described in the previous paper ${ }^{[24]}$. Fifty microliters of the buffered solution with ALA permeated was treated with a mixture of $3.5 \mathrm{ml}$ of acetylacetone, ethanol, and water (15:10:75 in volume ratio) containing $4 \mathrm{~g}$ of sodium chloride per liter, followed by the addition of $450 \mu 1$ of $85 \mathrm{ml} / 1$ aqueous formaldehyde solution. The treated solution was heated in boiling water for $30 \mathrm{~min}$, cooled in cold water for $5 \mathrm{~min}$. These reactions eventually gave us the fluorescent ALA derivative, 2-methyldeneamin-3,5-diacetyl-

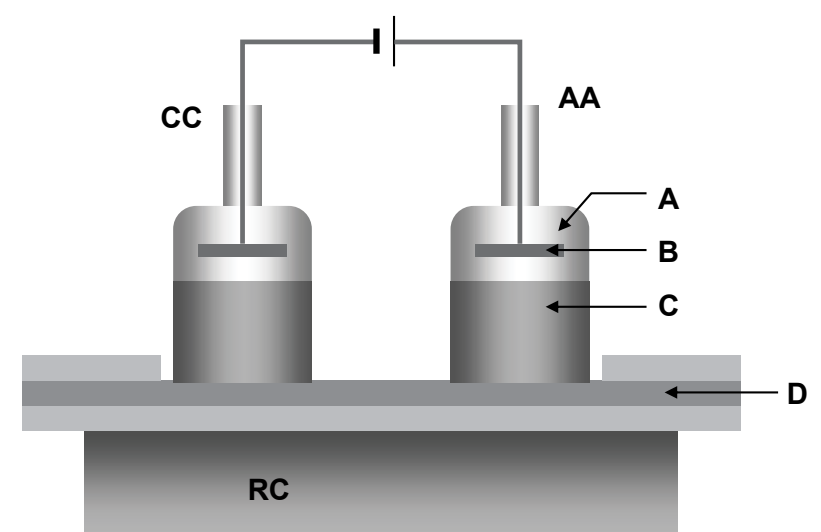

Fig. 1: Schematic representation of iontophoretic device used RC: Receiver compartment; $C$ : cathode cell; $A A$ : anode cell (donor compartment); A: agar gel, B: platinum electrode, $\mathrm{C}$ : electrolyte, D: YMP skin

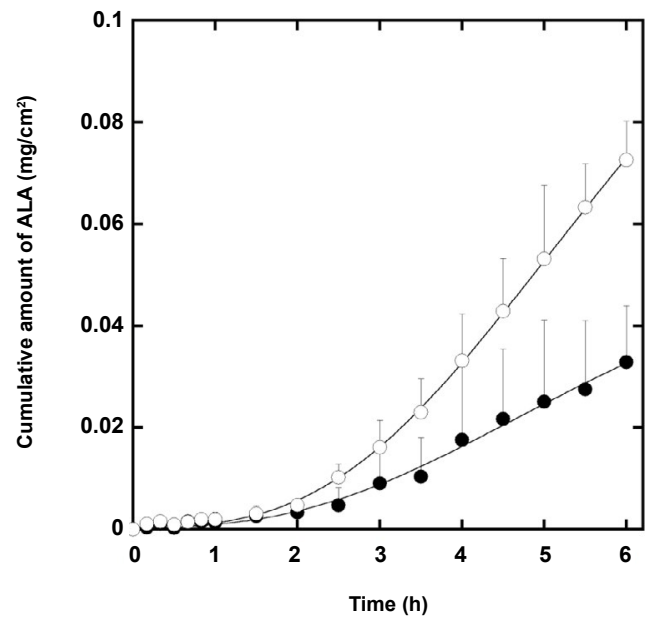

Fig. 2: ALA permeation through YMP full-thickness skin by iontophoresis with and without ethanol Changes in cumulative amounts of ALA permeated through YMP full-thickness skin with permeation time by iontophoresis with and without ethanol. Values are mean $\pm S D(n=3)$. The ALA solution with $20 \%$ ethanol (- - $E W=20: 80)$ and without ethanol (-०—, $E W=0: 100)$ was employed as a sample 
4,6-dimethylphenylpropionic acid. The fluorescence intensity of the ALA derivative was measured with a fluorescence spectrophotometer (FP-6500, Jasco Co.). The excitation and emission wavelengths were 363 and $473 \mathrm{~nm}$, respectively.

Fig. 2 shows the change in cumulative amount of iontophoretically permeated ALA per unit YMP fullthickness skin area with the permeation time. The ALA solution with $20 \%$ ethanol by weight $(E W=20: 80)$ and without ethanol $(\mathrm{EW}=0: 100)$ was employed as a sample. The concentration of ALA was $0.6 \mathrm{~mol} / 1$ in both the samples. In these iontophoretic deliveries, the cumulative amount of ALA increases with increasing permeation time. In comparison at the same permeation time, moreover, the cumulative amount of ALA in the iontophoretic delivery with $20 \%$ ethanol is greater than that without ethanol. Since the dielectric constant of ethanol $\left(24.6\right.$ at $\left.20^{\circ}\right)$ is lower than that of water $\left(78.6\right.$ at $\left.20^{\circ}\right)$, the addition of ethanol probably inhibits ionization of ALA molecules. We then expected that ethanol suppressed ALA permeation in iontophoretic delivery. Contrary to our expectation, however, ethanol enhances the iontophoretic permeation of ALA through YMP skin.

Next, the permeation parameters were evaluated and estimated from the permeation profile shown in fig. 2 . The flux, $J$, of ALA permeated through YMP skin was calculated from the slope of the steady-state portion of the permeation profile between the cumulative amount of permeated ALA per unit skin area and the permeation time ${ }^{[25]}$. The lag time, $T_{\text {lag }}$, which is the time at the beginning of permeation, was also estimated from the linear extrapolation of the steady-state portion to the $\mathrm{X}$-axis of the permeation profile. Furthermore, calculated the permeability coefficient, $K_{p}$, diffusion coefficient, $D$, and partition coefficient, $K$, of ALA using the following Eqn. 1. $K_{p}=J / C_{D}=K D / L$ and Eqn. $2: T_{\text {lag }}=$ $L^{2} / 6 D$, where $C_{D}$ is the initial concentration of ALA in the donor compartment and $L$ is the diffusion path

TABLE 1: PERMEABILITY COEFFICIENT, LAG TIME, DIFFUSION COEFFICIENT, AND PARTITION COEFFICIENT OF ALA IN IONTOPHORESIS WITH AND WITHOUT ETHANOL

\begin{tabular}{ccccc}
\hline EW & $\begin{array}{c}K_{p} \\
\left(\times 10^{-5} \mathrm{~cm} / \mathrm{h}\right)\end{array}$ & $T_{\text {lag }}(\mathrm{h})$ & $\begin{array}{c}D \\
\left(\times 10^{-3} \mathrm{~cm}^{2} / \mathrm{h}\right)\end{array}$ & $K\left(\times 10^{-3}\right)$ \\
\hline $0: 100$ & $8.08 \pm 2.16$ & $2.08 \pm 0.88$ & $3.75 \pm 1.98$ & $4.73 \pm 1.50$ \\
$20: 80$ & $19.28 \pm 1.16 *$ & $2.26 \pm 0.32$ & $2.99 \pm 0.45$ & $13.00 \pm 1.16^{*}$ \\
\hline
\end{tabular}

The ALA solution with 20 wt. \% ethanol $(E W=20: 80)$ and without ethanol ( $E W=0: 100)$ was employed as a sample. ${ }^{*} P<0.01$ by Student's $t$-test. Permeability coefficient $\left(K_{p}\right)$, lag time $\left(T_{\text {lag }}\right)$, diffusion coefficient $(D)$, and partition coefficient $(K)$ length, that is, the thickness of YMP skin. According to the previous paper, $0.2 \mathrm{~cm}$ to $L$ was assigned in this study ${ }^{[26]}$.

The permeation parameters calculated are summarized in Table 1 . As a result, the addition of $20 \mathrm{wt} . \%$ ethanol enlarges the $K_{p}$ of ALA in the iontophoretic delivery by a factor of approximately 2.5 ( $\mathrm{p}<0.01$ by Student's $t$-test). The $T_{\text {lag }}$ of ALA in the iontophoretic delivery with 20 wt. \% ethanol was almost equal to that without ethanol. Furthermore, the $D$ was almost constant in the iontophoretic delivery with and without ethanol, but the $K$ was much larger in the iontophoretic delivery with ethanol than without ethanol $(\mathrm{p}<0.01)$.

Compared to the $K_{p}$ in the passively transdermal delivery with $40 \%$ ethanol, $2.40 \times 10^{-5} \mathrm{~cm} / \mathrm{h}$, which was estimated in previous reports ${ }^{[27]}$, the $K_{p}$ of ALA in the iontophoresis, shown in Table 1, becomes larger, regardless of ethanol. An aqueous ALA solution is acidic; for instance, $\mathrm{pH}$ of $0.6 \mathrm{~mol} / \mathrm{l}$ ALA solution is 1.9. Since $\mathrm{pKa}$ of ALA in water at $25^{\circ}$ is 4.1 and $8.9^{[28]}$, moreover, ALA molecules are likely to be converted into the positively charged ions. Hence, the charged ALA ion is repelled by the similarly charged anodal electrode and is absorbed readily through the skin by the iontophoresis, which enhances the ALA skin permeation.

Along with fig. 2, the $K_{p}$ of ALA in Table 1 indicates that the ALA permeation was accelerated by ethanol. From Eqns. 1 and 2, the transdermal delivery of a drug was governed by $D$ and $K$ of the drug. As shown in Table 1 , the $K$ of ALA in the iontophoretic delivery was significantly enlarged by ethanol, but the $D$ was almost constant. It is considered, therefore, that ethanol enhances the partition of ALA into YMP full-thickness skin, leading to acceleration of permeation of ALA in iontophoretic delivery.

The $K_{p}$ of ALA in the passively transdermal delivery with $20 \%$ ethanol was not estimated in this study, but is probably the same as or less than that with $40 \%$ ethanol, $2.40 \times 10^{-5} \mathrm{~cm} / \mathrm{h}$, mentioned above. Also, the $K_{p}$ of ALA in the iontophoretic delivery without ethanol was $8.08 \times 10^{-5} \mathrm{~cm} / \mathrm{h}$. The summation of $K_{p}$ of ALA in each delivery, $10.48 \times 10^{-5} \mathrm{~cm} / \mathrm{h}$, was then less than the $K_{p}$ in the iontophoretic delivery with $20 \%$ ethanol, $19.28 \times 10^{-5} \mathrm{~cm} / \mathrm{h}$. That is to say, the combination system of iontophoretic delivery and ethanol has a synergistic effect on the ALA skin permeation.

Anodal iontophoresis brings about not only flux of cationic ions, but also flux of a solvent owning to 
electroosmosis $^{[29]}$. Electroosmosis can also deliver neutral compounds such as urea, mannitol, and sucrose ${ }^{[30]}$. In this study, the electroosmotic flux of ethanol may occur in the mixed solvent and readily penetrates it into the YMP full-thickness skin, which gives rise to the synergistic effect of the combination system of iontophoresis and ethanol on the ALA skin permeation.

It is concluded that the addition of $20 \%$ ethanol into an aqueous ALA solution enhances the iontophoretic delivery of ALA through YMP full-thickness skin. However, it is suspected that the addition of excess amount of ethanol reduces the iontophoretic effect on the ALA permeation, because of its low dielectric constant. Further studies are needed to confirm the optimum concentration of ethanol for iontophoretic delivery of ALA.

\section{Acknowledgements:}

The authors would like to thank Yuko Ishii for her technical assistance in the early stage of this work.

\section{Conflicts of interest:}

The authors declare that there is no conflict of interests in this paper.

\section{Financial support and sponsorship:}

Nil.

\section{REFERENCES}

1. Blume JE, Oseroff AR. Aminolevulinic acid photodynamic therapy for skin cancers. Dermatol Clin 2007;25(1):5-14.

2. Babilas P, Landthaler M, Szeimies RM. Photodynamic therapy in dermatology. Eur J Dermatol 2006;16:340-8.

3. Itoh Y, Ninomiya Y, Tajima S, Ishibashi A. Photodynamic therapy of acne vulgaris with topical 5-aminolevulinic acid and incoherent light in Japanese patients. $\mathrm{Br} \mathrm{J}$ Dermatol 2011;144(3):575-9.

4. Kimura M, Itoh Y, Tokuoka Y, Kawashimam N. DeltaAminolevulinic Acid-Based Photodynamic Therapy for Acne on The Body. J Dermatol 2004:31:956-60.

5. Kurwa HA, Barlow RJ. The Role of Photodynamic Therapy in Dermatology. Clin Exp Dermatol 1999;24(3):143-8.

6. Castano AP, Demidova TN, Hamblin MR, Mechanisms in photodynamic therapy: part one-photosensitizers, photochemistry and cellular localization. Photodiagnosis Photodyn Ther 2004;1:279-93.

7. Bonnett R. Chemical Aspects of Photodymanic Therapy. Amsterdam: CRC Press; 2000.

8. Hikima T, Maibach H. Skin Penetration Flux and Lag-Time of Steroids Across Hydrated and Dehydrated Human Skin in vitro. Biol Pharm Bull 2006;29:2270-73.

9. Nakaseko H, Matsumoto Y. Photodynamic therapy in the dermatological field. JJSLSM 2006;27:303-8.

10. Langkjaer L, Brange J, Grodsky GM, Guy RH. Iontophoresis of monomeric insulin analogues in vitro: effects of insulin charge and skin pretreatment. J Control Release 1998;51(1):47-56.

11. Pillai O, Borkute SD, Sivaprasad N, Panchagnula R. Transdermal iontophoresis of insulin. II. Physicochemical considerations. Int J Pharm 2003;254:271-80.

12. Vemulapalli V, Banga AK, Friden PM. Optimization of iontophoretic parameters for the transdermal delivery of methotrexate. Drug Deliv 2008;15:437-42.

13. Nair A, Vyas H, Shah J, Kumar A. Effect of permeation enhancers on the iontophoretic transport of metoprolol tartrate and the drug retention in skin. Drug Deliv 2011;18:19-25.

14. Kanebako M, Inagi T, Takayama K. Transdermal delivery of indomethacin by iontophoresis. Biol Pharm Bull 2002;25:779-82.

15. Smyth HD, Becket G, Mehta S. Effect of permeation enhancer pretreatment on the iontophoresis of luteinizing hormone releasing hormone (LHRH) through human epidermal membrane (HEM). J Pharm Sci 2002;91:1296-307.

16. Lopez RF, Bentley MV, Delgado-Charro MB, Guy RH. Iontophoretic delivery of 5-aminolevulinic acid (ALA): effect of pH. Pharm Res 2001;18:311-5.

17. Lopez RF, Bentley MV, Begoña Delgado-Charro M, Guy RH. Optimization of aminolevulinic acid delivery by iontophoresis. J Control Release 2003;88:65-70.

18. Boddé HE, Roemelé PE, Star WM. Quantification of topically delivered 5-aminolevulinic acid by lontophoresis across ex vivo human stratum corneum. Photochem Photobiol 2003;75:418-23.

19. Mizutani K, Watanabe D, Akita Y, Akimoto M, Tamada Y, Matsumoto Y. Photodynamic therapy using direct-current pulsed iontophoresis for 5-aminolevulinic acid application. Photodermatol Photoimmunol Photomed 2009;25:280-2.

20. Omi T, Akimoto M, Miyazaki M, Kawana S. Iontophoresisenhanced cutaneous absorption of 5-aminolevulinic acid shortens the incubation period in photodynamic therapy. Laser Ther 2009;18:143-9.

21. Krishnan G, Roberts MS, Grice J, Anissimov YG, Benson HA. Enhanced transdermal delivery of 5-aminolevulinic acid and a dipeptide by iontophoresis. Biopolymers 2011;96:166-71.

22. Nishimura T, Akimoto M, Miyazaki M, Nomoto M, Miyakawa M. Developments of Transdermal Transport System during Skin Iontophoresis and Electroporation. PIERS online 2010;6:759-63.

23. Lachenmeier DW. Safety evaluation of topical applications of ethanol on the skin and inside the oral cavity. J Occup Med Toxicol 2008;26:1-16.

24. Okayama A, Fujii S, Miura R. Optimized Fluorometric Determination of Urinary $\delta$-Aminolevulinic Acid by Using Pre-Column Derivatization and Identification of the Derivative. Clin Chem 1990;36:1494-7.

25. Azzi C, Zhang J, Purdon CH, Chapman JM, Nitcheva D, Hebert JR, et al. Permeation and reservoir formation of 4-(methylnitrosamino)-1-(3-pyridyl)-1-butanone (NNK) and benzo[a]pyrene $(\mathrm{B}[\mathrm{a}] \mathrm{P})$ across porcine esophageal tissue in the presence of ethanol and menthol. Carcinogenesis 2006;27:137-45.

26. Fujii M, Yamauchi S, Nagakura M, Takeda Y, Matsumoto M. Enhancement effect of menthoxypropandiol and menthol on 
the penetration of indomethacin through Yucatan micropig skin in vitro. Drug Deliv Sys 1997;12:127-31.

27. Tokuoka Y, Suzuki M, Ohsawa Y, Ochiai A, Ishizuka M, Kawashima N. Enhancement in skin permeation of 5-aminolevulinic acid using 1-menthol and its derivatives. Drug Dev Ind Pharm 2008;34:595-601.

28. Donnelly RF, McCarron PA, David Woolfson A. Derivatives of 5-Aminolevulinic Acid for Photodynamic Therapy. Perspect Medicin Chem 2007;1:49-63.

29. Dhote V, Bhatnagar P, Mishra PK, Mahajan SC, Mishra DK. Iontophoresis: A Potential Emergence of a Transdermal Drug Delivery System. Sci Pharm 2012;80(1):1-28.

30. Li SK, Peck KD. Passive and Iontophoretic Transport through the Skin Polar Pathway. Skin Pharmacol Physiol 2013;26(46):243-53. 